\title{
Do Nerd ao Geek: Uma Análise dos Simbolismos de Representatividade e Práticas de Consumo
}

Felipe Barros da Silva Mendes ${ }^{1}$

Lucas Melo Ferreira Silva²

Resumo: O presente trabalho visa discutir e analisar, a cultura pop dentro da perspectiva dos grupos identitários nerd e geek, a fim de compreender as transformações simbólicas e de representatividade ao longo dos anos e como o mainstream contribuiu para que heróis de histórias em quadrinhos e filmes blockbusters se tornassem notícia nos canais midiáticos, reinventando o estereótipo do nerd criado pela indústria cinematográfica. Além disso, o artigo traz um aparato sobre o consumo nerd/geek e o atual cenário pandêmico no qual o mundo vivencia, levantando a hipótese de que a sociedade de consumo adquiriu algumas das características que compõem a cultura desses grupos identitários em razão das regras de isolamento social impostas pela pandemia.

PALAVRAS-CHAVE: Nerd. Geek. Representatividade. Estereótipo. Covid-19. Introdução

A contemporaneidade é constituída por uma enorme gama de elementos e fenômenos do consumo. É comum que os indivíduos em geral sejam acríticos acerca da origem e impacto, social ou econômico, do consumo no conjunto em que vive, se apegando apenas ao resultado final produzido por ele e deixando no esquecimento toda a trajetória histórica e societária de um fenômeno como esse na sociedade.

Com o advento da globalização, os indivíduos, em uma necessidade de se identificarem e se diferenciarem dos demais, reúnem-se em grupos que partilham dos mesmos gostos e práticas de consumo. Segundo Maffesoli (1998) as pessoas vivem como celibatários, mas o fato de estarem sozinhas não significa que estejam solitárias. Pelo contrário, os processos culturais e as mudanças sociais fizeram o individualismo dos sujeitos ser substituído pela carência de identificação com determinadas tribos sociais.

Para Blass (2008), as tribos são um conjunto de indivíduos que se unem por ideais em comum, mas não necessariamente por compartilharem os mesmos objetivos. O termo

1 Graduando do Curso de Comunicação Social pela Universidade Federal de Pernambuco do Campus Acadêmico do Agreste. E-mail: felipe.barrosmendes@hotmail.com

2 Graduando do Curso de Comunicação Social pela Universidade Federal de Pernambuco do Campus Acadêmico do Agreste. E-mail: lucas.mfsilva00@gmail.com 


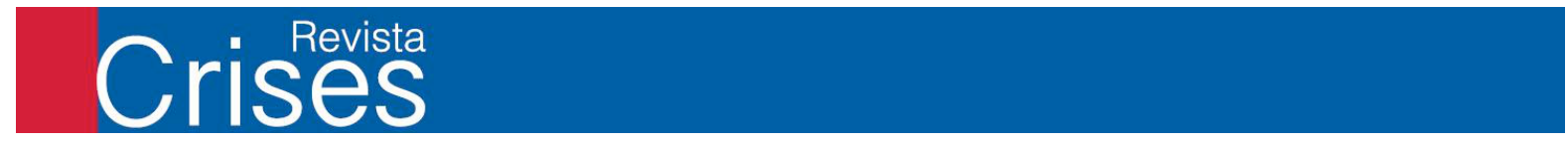

mais adequado a esses grupos hoje são as chamadas "tribos urbanas", ou seja, os agrupamentos e costumes presentes no cotidiano das cidades. Os participantes desses agrupamentos compartilham de comportamentos, vocabulários, maneirismos e vestuário, por exemplo.

Uma tribo não se restringe apenas ao território regional físico, ela pode ter integrantes de todas as partes do mundo, mesmo que eles não tenham nenhum tipo de contato ou se conheçam, configurando dessa maneira que a tribo é global e, por sua vez, extensa. Um exemplo de "tribo urbana" que possui essas características são a dos nerds, os mesmos estão presentes por todo o globo e não necessariamente conhecem uns aos outros. Os processos identitários, suas práticas de consumo e interesses em comum caracterizam o nerd como uma tribo/cultura. Segundo Maffesoli (1998), cada pessoa tem um papel na sociedade, cada um dos indivíduos vivem em relação aos outros, as personalidades de cada um são formuladas em conjunto. Dessa forma, a partir do momento em que os nerds ressaltam suas individualidades, acabam criando um ambiente simbólico e comunitário de transferência de bens e ideias.

Mas afinal, o que seria um nerd? Fernandes e Rios (2011), apontam que o termo surgiu inicialmente nos anos 1950 em um livro de Theodore Seuss Geisel, a palavra foi utilizada para denominar um personagem considerado estranho/esquisito. Já Silva e Souza (2013) apontam que o termo surgiu a partir da sigla do laboratório "Northern Electric Research and Development" (NERD), dessa maneira, a expressão nerd é relacionada ao meio tecnológico, especialmente o da informática e o digital.

Independente da sua origem, não há como negar que a cultura nerd está difundida em todos os meios, sua introdução às práticas de consumo se deu em meados dos anos 1970, com os lançamentos dos filmes do universo Star Wars, dos jogos de fliperama, como Spacewar e de aparelhos tecnológicos, um exemplo são as câmaras de revelação instantânea, as polaroids. Entretanto, antes disso, produções norte-americanas de televisão, como Star Trek, e a venda massiva de quadrinhos, fomentaram o que anos depois conhecemos como "Cultura Pop". O estilo de vida chegou a sua consagração apenas na década de 1990, perpetuando até os dias de hoje, apesar de ser fortemente estereotipado no mainstream ${ }^{3}$, pois é um grupo que apresenta um grande espaço na

3 Termo utilizado para as mídias que expressam uma tendência ou moda principal. 


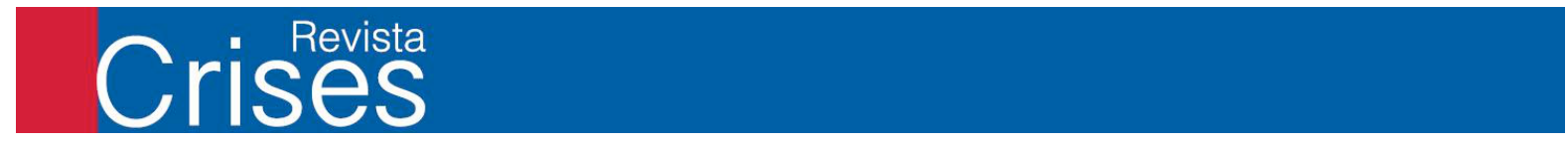

sociedade de consumo atual.

Diante disso, o presente artigo visa analisar e discutir a forma como são constituídos os grupos identitários nerd e geek, e a cooptação deles pela cultura do mainstream. Além disso, o trabalho se coloca dentro das atuais discussões que rondam o contexto pandêmico ao argumentar também sobre a hipótese de que o consumo da sociedade em geral adotou hábitos já praticados por esses dois grupos citados.

\section{O Nerd}

Nas últimas duas décadas, o "ser nerd" sofreu uma alteração simbólica, saindo de um excluído e estereotipado jovem cheio de espinhas e antissocial dos filmes de adolescentes americanos, para um sujeito que está atualizado às novas tecnologias e as novidades do mercado do entretenimento.

Como explica a especialista em comunicação e cultura, Lia Amancio,

O nerd não mudou. Ele continua sendo aquele cara completamente ligado e entendido sobre certos assuntos, como tecnologia e quadrinhos. O que mudou foi a cultura atual, que valoriza isso. Os nerds querem ser nerds e as pessoas querem ter nerds por perto (AMANCIO, 2011).

Essa valorização do estilo de ser nerd está fortemente associado ao sucesso financeiro de integrantes desse grupo atualmente, isto é, aqueles adolescentes que antes eram excluídos socialmente e focados nos estudos, nas descobertas do conhecimento e inovação, agora são bem sucedidos em diversas carreiras mundo afora. Um dos casos mais conhecidos de nerds que hoje possuem boa condição financeira, é o fundador da empresa Microsoft, considerado por anos o homem mais rico do mundo, segundo dados da revista Forbes, Bill Gates. Benjamin Nugent (2011), autor do livro "Nerd Americano: A História do Meu Povo", diz que "parte do que trouxe os nerds para o mainstream cultural foi o fato de o Bill Gates fazer parte do grupo".

Além da ascensão financeira e empreendedora de Gates, a produção midiática, em especial a de Hollywood, foi outro fator que influenciou essa valorização da cultura nerd. O mainstream está cada vez mais preocupado em representar o nerd de maneira mais fiel com a realidade, retirando estereótipos, de uma forma que os integrantes desse grupo não sejam mais alvo de repressão social, antes: 
estereotipados e considerados apenas indivíduos inadequados socialmente, hoje os nerds começam a ser vistos como consumidores privilegiados e criadores de tendências. O que antes era um xingamento passa a ser levantado como bandeira, estampado em camisetas e motivo de orgulho para alguns. Este novo cenário aponta para o surgimento de uma cultura juvenil centrada no consumo talvez mais do que qualquer outra e que traz a disputa simbólica para o primeiro plano (MATOS, 2011, p. 12).

Essa transformação da visão da sociedade ainda resultou em outro marco de mudança, agora o termo mais utilizado para designar nerd é o geek. Segundo dados da pesquisa do engenheiro de software, Burr Settles, que estudou mais de 2 milhões de tuítes em 2013, por meio de palavras mais associadas aos termos, mostra que a diferença entre nerd e geek é: os nerds estão mais relacionados ao conhecimento e estudos, enquanto os geeks estão mais ligados na cultura pop e entretenimento (filmes, séries, quadrinhos, entre outras coisas que o leve para o lúdico). Isso mostra que ocorreu uma eufemização do termo que já fora tão carregado de negatividade para um grupo social, comprovando que a sociedade atual está mais "amigável" e receptiva com os sujeitos que fazem parte dessa tribo urbana;

a primeira significação do termo nerd teria mudado com o tempo e, neste início de século XXI, teria ganho um significado mais positivo em função do lugar privilegiado que vêm recebendo as tecnologias virtuais e digitais. Juntamente com essa possível mudança de significado, o termo nerd foi associado a outro termo - geek - para referir as pessoas interessadas em tecnologia buscando escapar da conotação pejorativa inicial (BICCA et. al.,2013, p. 89).

Hoje, a categoria dos nerds/geeks apresenta inúmeras divisões internas, subcategorizando-se em pequenos nichos, no qual seus participantes se agrupam por meio de suas afinidades com as temáticas que estão sob o guarda-chuva produtivo do universo geek, como RPG (Role Playing Gaming), jogos de tabuleiro no geral, jogos eletrônicos, histórias em quadrinhos (HQs), filmes, séries, livros, músicas, cosplays ${ }^{4}$, tecnologia, dentre outros. Os indivíduos podem transitar entre essas subcategorias do grupo geral e assim acumular uma pluralidade de nichos que possuem afinidade, por exemplo, um jovem pode se sentir satisfeito com o consumo de RPGs e livros, já outro

4 Termo em inglês, formado pela junção das palavras costume (fantasia) e roleplay (brincadeira ou interpretação). É considerado um hobby onde os participantes se fantasiam de personagens fictícios da cultura pop japonesa. 
com filmes, cosplays e games.

Esses exemplos dados são alguns dos objetos consumidos dentro desse vasto universo, como mostra a imagem a seguir:

Ilustração 1 - Infográfico Evolução da Cultura Nerd

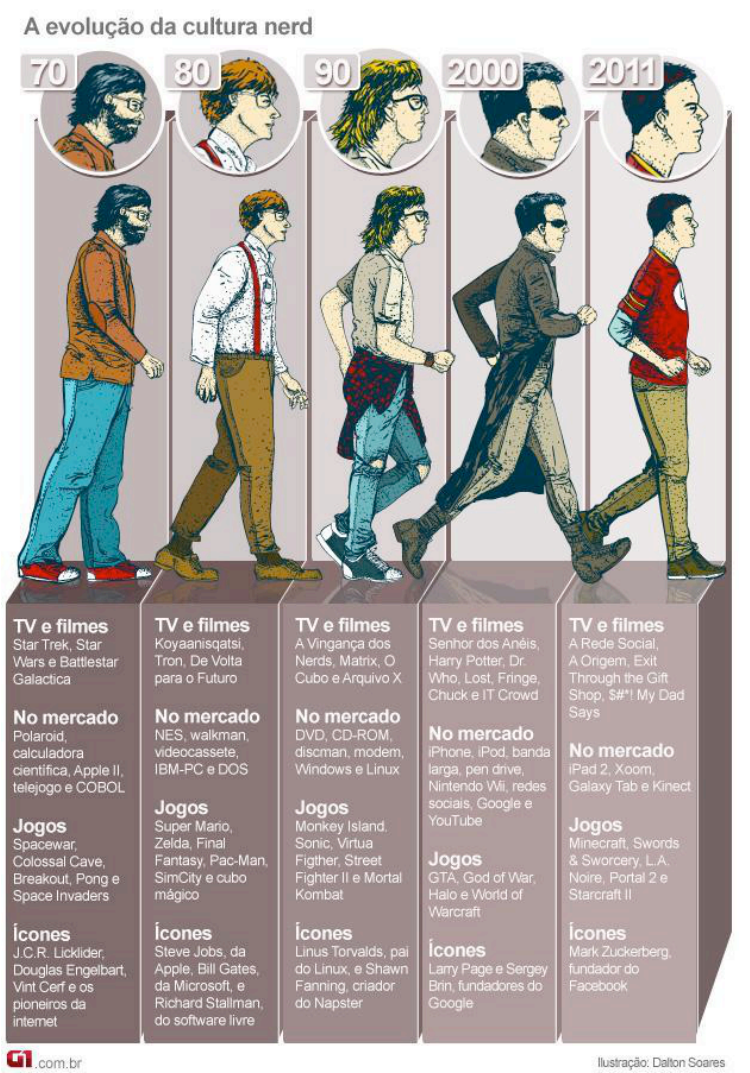

Fonte: $\mathrm{G} 1.5$

Nota-se que o consumo do mundo nerd/geek sofre alterações à medida que o nerd começa a ser notado por uma visão menos estereotipada e negativa, assim o consumo desses bens foram além de entrarem em ascensão, criando um mercado multimilionário.

Essa construção do repertório de temas de maior afinidade representam de uma certa maneira a formação identitária do sujeito em questão. Essa simpatia do sujeito por tais assuntos é demonstrada de forma discreta no cotidiano, por meio de camisetas, acessórios e afins, e exposta com mais intensidade quando estão próximos a outros indivíduos que partilham da mesma construção simbólica do ser ou em momentos

5 Disponível em: http://g1.globo.com/tecnologia/noticia/2011/05/nerds-transformam-opinioes-e-viram-osnovos-queridinhos-da-sociedade.html. Acesso em: 20 de Out. 2019. 


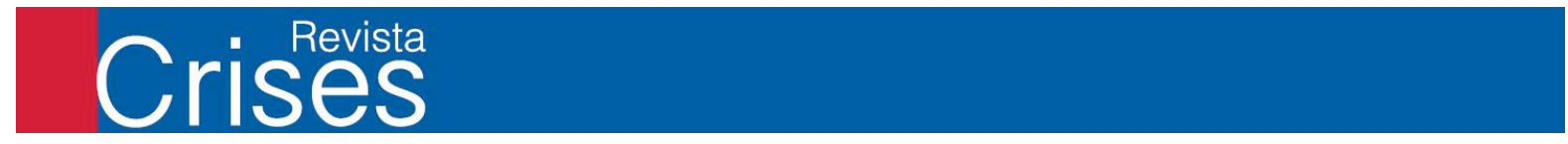

específicos, como, por exemplo, em eventos desse universo, que é o caso da Comic Con que ocorre em San Diego na cidade da Califórnia, EUA, umas das grandes convenções multi-gênero da cultura pop que atrai diversos fãs do mundo inteiro que se identificam com o que se é exposto nos stands durante um período de quatro dias.

\section{O Geek e o consumo}

Partindo do princípio que identidade é a junção de características que individualizam os indivíduos, pode-se notar que inúmeras características podem ser atribuídas geek. Pai e Zanella (2012), afirmam que a melhor definição para o geek seria "apaixonado", pois entre escolher uma blusa de um super-herói no camelô, por um preço inferior, ele optaria pela blusa oficial de maior significância, pois segundo Santaella \& North (2010, apud Caixeta e Martins, 2012, p. 155) “Os produtos não apenas denotam seu uso e valores de troca, mas também conotam significados estéticos, emocionais e míticos."

Nesse sentido, essa relação identitária e de consumo dos geeks pode ser relacionada com o conceito de simbolismo. Cassirer (1944 in Levy, 1999) propõe que cada ser humano habita em um mundo de símbolos, e cada um utiliza de um processo de simbolização para refletir acerca do mundo tangível ao seu redor e modificá-lo de alguma forma (Wilkie, 1994). Os indivíduos criam vínculos simbólicos com suas vivências para se relacionarem com o real e com os outros sujeitos sociais. Desta forma, por ser parte inerente da psique humana, os processos simbólicos são um aspecto essencial das práticas de consumo das pessoas.

O simbolismo age dentro da esfera consumista como agente propiciador de sentimentos e signos, relacionando-os com o processo de compra de algum bem e com isso agregando valor e experiências na mente dos consumidores (Wilkie, 1994). Assim, o sujeito transfere significados, ou seja, associações simbólicas para bens ou serviços, como por exemplo os action-figures,bonecos em miniaturas de personagens das produções midiáticas, que além de possuírem valor de troca elevado, dispõem de uma certa associação sentimental e de prestígio social dentro do grupo do indivíduo. Sendo assim, os objetos consumidos por esses indivíduos representam para eles uma simbologia própria, pois, como foi dito, é o próprio sujeito que classifica o que 
determinado item representa para o seu ser.

Essa atribuição simbólica feita pelo sujeito interfere na criação de sua autoimagem, que representa os sentimentos que o indivíduo possui de si mesmo. Dessa forma, "a necessidade do indivíduo de agir coerentemente com seu autoconceito torna a percepção de si próprio a base da personalidade humana e mantém a autoestima, por isso é importante" (WOLF, 2002, p.5).

Nesse sentido, a quantidade de bens que uma determinada pessoa possui exerce um papel importante na construção de sua identidade, como se os símbolos associados aos bens fossem uma extensão do ser. Esses processos de identificação e simbolismo ocasionam, de uma certa maneira, um consumo na esfera do intangível, ou seja, o ato de comprar, hoje, está mais voltado ao consumo dos símbolos e associações que determinados produtos possuem e que respaldam na construção ideológica dos indivíduos.

Para os geeks, o consumo de produtos como camisetas, posters, filmes, séries, action-figures, jogos, entre outros itens, o legitima dentro do grupo que está inserido. Estes objetos representam uma maneira de revelar à sociedade um pouco de sua personalidade e suas predileções. Com o consumo de quadrinhos, por exemplo, o geek se reafirma como geek. Dessa forma, os objetos de consumo da cultura pop dão sentido à vida de quem consome e não podem de forma alguma ser excluídos de suas relações sociais.

O mesmo ocorre de forma contrária, as produções multimídia do mainstream são influenciadas pelas práticas de consumo culturais dos indivíduos. O filme Capitã Marvel (2018), por exemplo, além de ser a vigésima primeira produção do universo cinematográfico do Marvel Studios, levanta uma bandeira de representatividade feminina, pois até então apenas a figura masculina era protagonista das produções. O mesmo acontece com o filme Mulher-Maravilha (2017) da DC Comics, primeira produção onde a protagonista de um filme baseado em quadrinhos de super-heróis é uma mulher. Outro exemplo de representatividade está no filme Pantera Negra (2018), também do Marvel Studios, que traz em sua narrativa um discurso de visibilidade negra, quebrando com o estereótipo do herói com traços caucasianos.

Os simbolismos atrelados a essas produções dão visibilidade aos grupos, minorias 


\section{Cising

ou não, pois criam lugares de fala que antes não eram dispostos para tais tribos, os representando de forma positiva nas mídias, atingindo novos grupos e, assim, gerando novos consumidores para esses produtos. Em consequência disso, o ser nerd, na personificação do geek, torna-se um grupo mais aceito na rede do social, pois as representações, como as apresentadas em Pantera Negra e Capitã Marvel, estão incluídas dentro desse grupo.

Séries como The Big Bang Theory (2007-2019), deram espaço para os nerds dentro da indústria do entretenimento, desmistificando e reforçando diversos estereótipos presentes no imaginário popular, tais quais apresentados por Galvão (2009), são: o fascínio pelos estudos, a inteligência acima da média, e a dificuldade de se relacionar com pessoas que não sejam semelhantes a eles.

A popularidade de séries como esta e a ascensão de produções audiovisuais baseadas em quadrinhos tornou o nerd mais popular, ressignificando a tribo. Esta popularidade também atrai o interesse de outros sujeitos que inicialmente não fazem parte do grupo ou não se consideravam geeks, estão apenas consumindo produtos advindos da cultura pop com a finalidade de se legitimar perante o social, indo de acordo com as tendências de moda comportamental e de consumo.

\section{0, o ano do plot-twist}

2020 foi um ano desafiador para todos, tanto em um aspecto social como em todas as outras áreas do conhecimento humano. Ninguém sabe ainda como qualificar este momento ao qual estamos vivendo. A vida teve sua rotina alterada devido a todas as normas de segurança implementadas para conter a pandemia da Covid-19 do mundo. Escolas fechadas, shows cancelados, comércio parado, esses foram alguns, dentre vários outros ambientes afetados pela doença, menos o consumo.

Essa necessidade capitalista de consumir, que hoje podemos considerar até uma necessidade fisiológica humana, encontrou no mundo virtual um meio de amplificar essa necessidade e de se manter firme na sociedade. Empresas fecharam suas portas físicas e abriram suas janelas para o mundo online, saciando o desejo de compra dos consumidores, que, por conta do isolamento social, foram levados a ficaram dentro de 


\section{Crie日o

casa. Assim sendo, o e-commerce ${ }^{6}$ tornou-se a principal ferramenta estratégica do mercado para manter o relacionamento entre marcas e pessoas. Apenas no Brasil, segundo dados Money Times ${ }^{7}$, essa modalidade de vendas online teve crescimento recorde de $47 \%$ durante a pandemia, esse número foi impulsionado por 90,8 milhões de pedidos nos primeiros seis meses de 2020. De acordo com Maia et al (2019, p.45):

"As empresas business-to-business (B2B) estão se adaptando com muito esforço a este novo cenário. A internet e canais de comunicação eram vistos como meios informativos com os clientes, sobretudo pelo fato de as compras nesse mercado serem muitas vezes individualizadas e as negociações serem específicas para cada comprador e fornecedor business-to-consumer (B2C)".

Dessa maneira, as empresas precisaram se reciclar e utilizar novas estratégias para cativar e engajar o público dentro desse cenário digital. Besanko et al. (2006) definem estratégia não como sendo respostas de adaptações com relação às alterações evidentes no espaço onde existem, mas como os princípios das empresas em relação ao ambiente que as cerca. Todavia, os autores põem em foco que uma estratégia bem realizada é resultante de uma determinada aplicação destes princípios, que não devem se contrapor às condições empresariais que estão em permanente mutação (FERNANDES et al., 2015; BESANKO et al., 2006). Mintzberg et al. (2010) caracteriza a estratégia como aquela na qual o planejamento se revela como um desafio na administração empresarial dos dias atuais, visto que, quando surge a necessidade de reorganização empresarial, é audacioso de alguma marca sair da zona de conforto e adentrar meios, temas e aspectos novos e não tão bem definidos, onde muitas das antigas movimentações gestoriais não se aplicam mais.

Um caso claro de reorganização e adaptação empresarial no atual cenário pandêmico em que nos encontramos é a da indústria cinematográfica, que devido ao fato do fechamento dos cinemas ao redor do mundo, se adaptou, ou procurou se adaptar, ao "novo normal" por meio das plataformas de streaming. Essa modalidade obteve durante o ano de 2020 um crescimento de $37 \%$, se comparado ao ano anterior, segundo estudo da Sherlock Communications ${ }^{8}$. Dentre as grandes plataformas de streaming por assinatura

6 Mercado eletrônico, em tradução livre para o português.

7 Site brasileiro de referências acerca do mercado financeiro.

8 Disponível em: https://www.sherlockcomms.com/pt/relatorio-stremaing-latam/ 


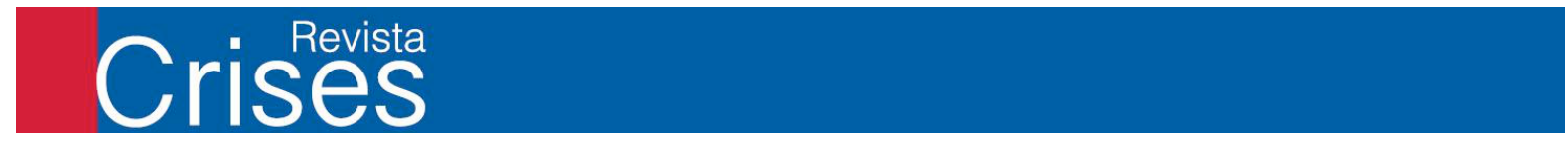

podemos destacar a produção original do Marvel Studios no Disney+, plataforma de acesso por assinatura aos filmes e séries da Disney, WandaVision, que de acordo com dados fornecidos para a plataforma de inteligência da Variety ${ }^{9}$ pelo provedor de análise da Tvision, atingiu um índice de 8.127 de audiência, 81 vezes maior que a soma de todas as outras séries consumidas no mês de janeiro de 2021.

Além disso, com a maioria das pessoas forçadas a ficar em casa, a Twitch, plataforma de streams de conversas, jogos, artes e música, alcançou números para além do esperado. Em 2020, a plataforma obteve um crescimento de $120 \%$ em termos de audiência. Outro aspecto a se destacar é o interesse pelos games que duplicou durante o período da pandemia. O streamer de Counter-Strike Global Offensive, Gaules, bateu recorde na Twitch Brasil com 390 mil viewers em Julho do referido ano. A Riot Games, proprietária de jogos como League of Legends e VALORANT, ultrapassou a marca de 200 mil espectadores com a final do campeonato brasileiro de $\operatorname{Lo} L^{10}$. A venda de jogos eletrônicos também superou os números estipulados para o ano, com um lucro estimado em US $\$ 77.2$ bilhões $^{11}$.

Dessa maneira, é perceptível que as produções com números recorde como WandaVision e os números astronômicos do mercado de jogos eletrônicos, nos levam a perceber a adesão das pessoas à cultura nerd/geek, dentro do cenário pandêmico. Dessa forma, o lifestyle desse grupo identitário, considerado anteriormente como "estranho", por passarem maior parte de seu tempo isolados socialmente, se tornou socialmente e devidamente aceito na cultura hegemônica mundial, o esquito virou o "novo normal".

Essa adesão da maior parcela da sociedade ao estilo de vida e cultura nerd/geek, além de ser exemplo de conduta sanitária em relação ao contágio da covid-19, pois propõe, de certa maneira, o isolamento social, proporcionou o aumento do consumo de produtos da Cultura Pop, movimentando bilhões de dólares ao redor do mundo, seja na compra de acessórios, produtos licenciados, plataformas de streaming ou jogos. Podemos concluir assim, que, 2020 foi o ano em que o "plot twist" aconteceu e os nerds/geeks finalmente se tornaram os "caras mais descolados do pedaço", um verdadeiro elogio ao

9 Disponível em: https://revistamonet.globo.com/Series/noticia/2021/03/serie-wandavison-ultrapassabridgerton-em-audiencia.html

10 Sigla para League of Legends.

11 Dados disponíveis em: https://blog.airfluencers.com/blog/mundo-geek-porque-esse-mercado-e-umsucesso/ 


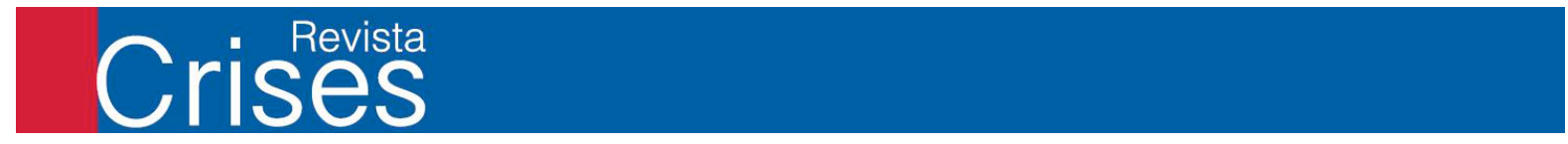

estilo filme da "Sessão da Tarde".

\section{Considerações Finais}

Portanto, conforme o exposto, a globalização uniu os indivíduos de todo o mundo que compactuam com os mesmo ideais dentro das chamadas tribos urbanas. Apesar dos diversos estereótipos e preconceitos, a cultura nerd permeia desde o início da década de 1970 até os dias atuais. Em função dos avanços tecnológicos e do mainstream estar cada vez mais dando ênfase a essa cultura, o agora "geek" torna-se popular, os signos que os afirmam como pertencentes da cultura nerd ainda estão presentes, assim como suas práticas de consumo que os individualizam perante a sociedade. Esses simbolismos que constroem a identidade do geek representam uma forma de expor a sociedade quem o indivíduo realmente é, dando sentido ao consumo dos objetos desta cultura que o rodeia, além das associações afetivas e agregação de valor aos objetos consumidos.

Assim, o trabalho buscou compreender a forma como o consumo se configura dentro de uma determinada tribo urbana, no caso a dos nerds, e como as práticas de consumo da sociedade, de uma forma geral, transforma essa tribo ao decorrer dos tempos.

Por isso, a análise trouxe alguns fundamentos e esforços comunicacionais, como os filmes e séries, de grande influência para a popularização da cultura nerd, tirando-os da visão marginalizada que tinham na sociedade. O texto ainda se faz relevante para outros áreas do conhecimento, como a área da psicologia e dos estudos da psicanálise, pelo fato de buscar compreender como se dá o processo de interpretação dos símbolos atrelados às práticas de consumo, assim como os fatores psicográficos e intangíveis moldam os padrões e comportamentos inconscientes de consumo dos indivíduos. Além de contextualizar o cenário pandêmico que o mundo vivencia com as práticas de consumo dos grupos enfocados no artigo, o que releva a importância para os estudos comunicacionais de estarem sempre em consonância com as mudanças das rotinas globais.

\section{Referências}




\section{Revisa

BESSANKO, D.; DRANOVE, D.; SHANLEY, M.; SCHAEFER, S. A Economia da

Estratégia. Porto Alegre: Bookman, 2006.

BICCA, Angela Dillmann Nunes; CUNHA, Ana Paula de Araújo; ROSTAS, Márcia Helena Sauaia Guimarães; JAHNKE, Max de Lima. Identidades Nerd/Geek na web: um estudo sobre pedagogias culturais e culturas juvenis. Conjectura: Filos. Educ., Caxias do Sul, v. 18 , n. 1, p. 87-104, jan./abr. 2013

BLASS, Leila Maria da Silva. Desfile e Tribos Urbanas: A diversidade no efêmero. In: PAIS, José Machado e BLASS, Leila Maria da Silva (org.) Tribos Urbanas: Produção Artística e Identidades. $1^{a}$ ed. São Paulo: Annablume, 2004. P. 211-230.

BRENTANO, Laura. Nerds transformam opiniões e viram os novos 'queridinhos' da sociedade. Disponível em:_http://g1.globo.com/tecnologia/noticia/2011/05/nerdstransformam-opinioes-e-viram-os-novos-queridinhos-da-sociedade.html. Acesso em: 20 de Out. 2019.

FERNANDES, I. G. M.; FIGUEIREDO, H. M.; COSTA JÚNIOR, H. L.; SANCHES, S.G.; BRASIL, A. "Planejamento estratégico: análise SWOT". Revista Conexão Eletrônica das Faculdades Integradas de Três Lagoas, vol. 8, n. 01, 2015.

FERNANDES, Luís Flávio; RIOS, Rosana. Enciclonérdia: Almanaque da cultura Nerd. 1. ed. São Paulo: Panda Books, 2011.

GALVÃO, Danielle. Os nerds ganham poder e invadem a TV. In: Revista Científica Intr@ciência 1(1):34-41, 2009.

LEVY, Ruggero. Do Símbolo à Simbolização: uma Revisão da Evolução da Teoria e as Repercussões sobre a Técnica Psicanalítica. Porto Alegre: Sociedade Psicanalítica de Porto Alegre, 1999. Não publicado.

MAFFESOLI, Michel. O tempo das tribos: o declínio do individualismo nas sociedades de massa. $2^{a}$ ed. Rio de Janeiro, 1998.

MATOS, Patrícia. O nerd virou cool: identidade, consumo midiático e capital simbólico em uma cultura juvenil em ascensão. 2011. Monografia (Conclusão de curso) Universidade Federal do Rio de Janeiro, Rio de Janeiro.

MINTZBERG, H.; AHLSTRAND, B.; LAMPEL, J. Safári da estratégia: um roteiro pela selva do planejamento estratégico. Porto Alegre: Bookman, 2010.

MOTTA, Guilherme.; GOUVEIA, Mariana. A pandemia, os games e o crescimento da Twitch. Disponível em: https://live.tt/pt/feeed/a-pandemia-os-games-e-o-crescimento-da- 


\section{Criseng

twitch/. Acesso em: 09/03/21.

PAI, Gustavo Henrique Dal; ZANELLA, Fábio Lucio. Star Wars: A força infinita da marca. Revista Advérbio, Volume VII, nº 13, 2012.

RHIMES, Shonda. Série 'WandaVison' ultrapassa 'Bridgerton' em audiência.

Disponível em:_https://revistamonet.globo.com/Series/noticia/2021/03/serie-wandavisonultrapassa-bridgerton-em-audiencia.html. Acesso em 09/03/21.

SILVA, Enildo Fernande de; SOUZA, Igor Ramady Lira de. Dos Hackers Aos Nerds:

Como um grupo outsider se torna estabelecido criando novos outsiders. 2013. Monografia (Conclusão de curso) - Universidade Federal do Rio Grande do Norte, Rio Grande do Norte.

STYCER, Mauricio. Mercado de streaming cresce nos EUA e no Brasil em 2020. Disponível em:https://www.uol.com.br/splash/colunas/mauriciostycer/2020/11/29/mercado-de-streaming-cresce-nos-eua-e-no-brasil-em-2020.htm? cmpid=copiaecola. . Acesso em: 09/03/21.

TAMANAHA, Nádia. Qual a diferença entre nerd e geek?. Disponível em: https://super.abril.com.br/mundo-estranho/qual-a-diferenca-entre-nerd-e-geek/. Acesso em: 20 de Out. 2019.

WILKIE, William L. Consumer Behavior. 3rd Edition. John Wiley \& Sons, Inc., 1994.

WOLF, Fabiane. (2002). Simbolismo no Comportamento do Consumidor: Construindo uma Nova Escala. 10.13140/RG.2.1.2948.5928. 